\title{
Fatores socioeconômicos e demográficos associados ao trabalho informal: 0 caso de Toritama, Pernambuco, Brasil
}

Breno Bittencourt Santos ${ }^{1}$

Valtemira Mendes Vasconcelos ${ }^{2}$

Resumo: $\mathrm{O}$ trabalho precário é prejudicial ao funcionamento da economia, à institucionalização do trabalho e à estabilidade do trabalhador. Apesar disto, parcelas expressivas de trabalhadores dependem deste tipo de inserção laboral. Neste artigo, partimos de uma discussão conceitual sobre o trabalho precário e de uma caracterização do município de Toritama para analisar quais fatores e em que medida eles influenciam na inserção no mercado de trabalho, na composição da renda da população, e demonstrar empiricamente a dependência e os prejuízos que parcelas expressivas daquela população apresentam com 0 trabalho precário.

Palavras-chave: Precarização; informalidade; indústria têxtil; desigualdades socioeconômicas; Brasil.

1 Pesquisador Visitante do Centro de Investigações e Estudos em Sociologia do Instituto Universitário de Lisboa (CIES-IUL) / Faculdade de Ciências Humanas e Sociais de Serra Talhada - Serra Talhada - Brasil - brenobt@yahoo.com.br

2 Programa de Pós-Graduação em Geografia da Universidade Federal de Pernambuco (UFPE) - Recife Brasil - valtemira@hotmail.com 


\section{SOCIOECONOMIC AND DEMOGRAPHIC FACTORS ASSOCIATED WITH INFORMAL WORK: THE CASE OF TORITAMA, PERNAMBUCO, BRAZIL}

Abstract: Precarious work is detrimental to the functioning of the economy, the labor institutionalization and worker stability. Despite this, significant portions of workers depend on this type of labor insertion. In this article we start from a conceptual discussion on precarious work and a characterization of Toritama municipality to analyze which factors and to what extent they influence the insertion in the labor market, the composition of the income of the population and empirically demonstrate the dependence and losses that significant portions of that population present with precarious work.

Keywords: Precariousness; informality; textile industry; socioeconomic inequalities; Brazil.

\section{Introdução}

Tradicionalmente, o trabalho precário ${ }^{3}$ é definido como um conjunto de práticas laborais pós-modernas que escapam às formas tradicionais de institucionalização e regulamentação do trabalho. Baseado no processo da flexibilização, o trabalho precário favorece à desinstitucionalização, impede a formação e estabilização da economia formal e desvaloriza a posição socioprofissional dos trabalhadores, que, diante da pressão por desempenharem funções produtivas, veem-se obrigados a exercerem funções desprotegidas, desvalorizadas e, muitas vezes, ilegais (NORONHA, 2003; ANTUNES, 2006, BARBOSA, 2009).

Apesar dos argumentos contrários à precarização, é preciso considerar que, a depender do contexto no qual as práticas laborais precárias ocorrem, elas representam, talvez, a única oportunidade de estabelecimento de um circuito econômico que converge para a formação de um mercado de trabalho, cuja existência e funcionamento se tornam condição imprescindível para a inserção de indivíduos na esfera produtiva, sem o qual seria impossível a sobrevivência numa sociedade capitalista (BARBOSA, 2009; LIMA, 2013).

\footnotetext{
3 Além de "trabalho precário", expressões como "trabalho atípico", "trabalho flexível" e "formas pós-modernas de trabalho" também se referem às formas não tradicionais de trabalho, caracterizadas pela vulnerabilidade das condições de trabalho, instabilidade de ganhos entre os trabalhadores e ausência de acesso à proteção social (KUMAR, 1997; CASTEL, 1998; HARVEY, 2006).
} 
Não se busca sustentar com isto que a precarização laboral pode tornar-se mais vantajosa do que as formas tradicionais de trabalho, nas quais o trabalho formal, o salário e as proteções sociais dele derivadas são a representação tradicional do capitalismo. Todavia, refletindo-se a respeito das novas dinâmicas do capitalismo globalizado e das transformações recentes ocorridas na esfera produtiva, nas relações laborais e nos mercados, torna-se inegável considerar que parcelas significativas de trabalhadores, inclusive com elevada qualificação profissional, são estimuladas a desempenharem funções laborais precárias, consonante com as características da produção flexível (ANTUNES, 2006; RABOSSI, 2008; BARBOSA, 2009; LIMA, 2013).

De uma perspectiva considerada clássica, a participação de trabalhadores em formas laborais precárias associa-se a determinados fatores socioeconômicos e demográficos, fazendo supor que a vulnerabilidade de grupos populacionais pode influenciar na sua inserção precária no mercado de trabalho. É assim, por exemplo, que os imigrantes, sobretudo ilegais, tendem a desempenhar em maior proporção formas precárias de trabalho do que os não migrantes (BECKER, 2006; DUARTE; FUSCO, 2008); e que as mulheres, pessoas de cores negra e parda e de baixa escolaridade tendem a apresentar maior participação nas formas precárias de trabalho, indicando que, pelo menos no Brasil, fatores como sexo, cor/ raça e escolaridade influenciam a participação precária no trabalho (CASTRO; BARRETO, 1998; ANTUNES, 2006; CASTRO, 2008; NOGUEIRA, 2009; ARAÚJO; LOMBARDI, 2013).

Diante dos novos processos de globalização e de reestruturação capitalista, não apenas a esfera da produção sofre transformações, mas, inclusive, os trabalhadores que desempenham formas precárias de trabalho apresentam alterações em suas características socioeconômicas e demográficas. O trabalho precário passa a ser desempenhado também por trabalhadores que não apresentam as tradicionais características de vulnerabilidade socioeconômica e simbólica. Ao contrário, muitos dos trabalhadores precários passam a apresentar alta escolaridade e trajetórias socioprofissionais ascendentes, o que leva a problematizar a tradicional associação entre vulnerabilidade socioeconômica e simbólica de grupos populacioanis e a precarização do trabalho (RABOSSI, 2008; LIMA, 2013).

Essas reflexões indicam que, longe de ser uma questão exclusivamente econômica, o fenômeno da precarização laboral apresenta relevantes clivagens sociais, sendo necessário compreender as novas relações existentes entre as características socioeconômicas e demográficas destes grupos e a inserção laboral precária no contexto de globalização e flexibilização recente. Diante disto, 
indaga-se: quais fatores socioeconômicos e demográficos e em que medida eles permanecem associados ao desempenho de funções produtivas precárias?

Pensando nos desdobramentos teóricos e práticos sinalizados pelos novos processos de globalização e pela nova informalidade, no presente artigo são feitas reflexões a respeito da precarização laboral no município de Toritama, município pernambucano situado na região Nordeste do Brasil, cuja população é marcada pela baixa qualificação educacional e profissional e pela dependência quase exclusiva dos trabalhadores na inserção laboral precária na indústria de confecções. Com esta análise, de natureza eminentemente quantitativa, busca-se analisar quais fatores socioeconômicos e demográficos estão associados à precarização do trabalho e às consequências monetárias disto para os trabalhadores que desempenham funções produtivas que, embora lhes permitam a sobrevivência material, os situam à margem de proteção institucional e que, no longo prazo, podem criar um contingente de ex-trabalhadores à margem de qualquer cobertura social.

\section{Breve discussão teórica sobre trabalho, precarização e nova informalidade}

Até o início do Século XIX, o trabalho era interpretado como qualquer atividade realizada pelos indivíduos, sem distinção de como era realizado ou de sua teleologia. Era considerado como uma atividade profundamente indigna, historicamente ligada à servidão, devendo ser realizado somente por aqueles que dependiam da venda de seu tempo e de sua força física para a sobrevivência (CASTEL, 1998; GRINT, 2002).

A partir da modernidade, as interpretações sobre o trabalho experimentaram profundas transformações. Na esfera produtiva, o trabalho passa a ser representado pelo emprego, caracterizado pelo assalariamento, rígida divisão/ especialização das funções e produção de bens para o consumo de massa. No contexto da reprodução social, o trabalho é interpretado como o elemento determinante da inscrição do indivíduo na estrutura social, responsável pela estruturação de toda a organização social, fator determinante na (re)produção das dimensões econômica, política, social e cultural, balizador das mais importantes formas de interação e base da definição identitária e da condição de cidadania e dignidade dos indivíduos (KUMAR, 1997; CASTEL, 1998; GRINT, 2002; HARVEY, 2006).

A interpretação do papel desempenhado pelo trabalho na modernidade começou a perder sua força a partir da primeira grande crise do emprego, ocorrida na déada de 1960, o que estimulou a substituição das formas modernas 
de trabalho por formas precárias, as quais provocaram mudanças na estrutura socioeconômica, política e cultural e ameaçavam a segurança do trabalhador. $\mathrm{O}$ recrudescimento da precarização pode ser interpretado como parte constitutiva do modelo de acumulação flexível, ${ }^{4}$ que, motivado pelo processo de reestruturação capitalista que buscava substituir o modelo fordista e retomar o crescimento econômico capitalista, gerou profundas alterações que não ficaram circunscritas à produção, mas impactaram em toda a organização social (KUMAR, 1997; HARVEY, 2006).

$\mathrm{Na}$ retórica capitalista, diante dos processos de globalização e reestruturação produtiva, a flexibilidade significa o meio estratégico para a retomada do crescimento econômico e a solução para o desemprego em massa, uma vez que diminui os custos de produção, permite a ampliação da produção industrial e a distribuição de mercadorias em nível mundial. Contudo, para os trabalhadores, especialmente nos países em desenvolvimento, cuja proteção jurídio-institucional é frágil ou inexistente, a flexibilização significa o aprofundamento da precarização, motivando os países industrializados a deslocarem sua produção e investir em países nos quais as garantias trabalhistas são mínimas, conseguindo reduzir seus custos de produção e, consequentemente, aumentar sua produtividade, competitividade e lucros (KUMAR, 1997; HARVEY, 2006; ANTUNES, 2006; LIMA, 2013).

A precarização do trabalho caracteriza-se pela redução da proteção jurídica, política, socioeconômica e simbólica ao trabalhador. As relações produtivas deixam de ser regulamentadas por meio de contratos de trabalho estáveis, com representação sindical e com garantias de proteções, a exemplo de salários predeterminados, aposentadorias e seguros. No Brasil, as formas laborais precárias podem ser representadas, em grande medida, pelas práticas de subcontratação, terceirização e informalidade.

A subcontratação e a terceirização correspondem a processos de externalização de atividades, isto é, consistem na transferência de atividades periféricas para serem executadas de forma autônoma por empresas e/ ou trabalhadores especializados. A diferença entre elas é que a subcontratação ocorre quando a empresa/ profissional é contratada para a execução de atividades diretamente ligadas ao objeto social do contratante, ao passo que as atividades terceirizadas

4 Diferentes expressões designam o novo modelo de produção e reprodução social que substituiu o fordismo, como "acumulação flexível", "pós-fordismo", "pós-industrialismo", "especialização flexível”, cada uma com referências teóricas e posições ideológicas específicas (KUMAR, 1997; GRINT, 2002; HARVEY, 2006). 
tendem a ser de apoio, não interferindo de forma direta na linha de produção do contratante (PINHEIRO, 1999; JINKINGS; AMORIM, 2006; ANTUNES, 2006)5.

Tradicionalmente, a informalidade ${ }^{6}$ refere-se às atividades realizadas exclusivamente como forma de obtenção de recursos, mas que, dadas as condições sob as quais são executadas, tendem a serem realizadas por trabalhadores empobrecidos, porém, não exclusivamente por esses, cujos produtos e serviços de baixo custo, livre de qualquer institucionalização, padronização e taxação de impostos, são direcionados para o consumo de grupos populacionais geralmente empobrecidos, embora também não exclusivamente a estes (CACCIAMALI, 1994; NORONHA, 2003; BARBOSA, 2009).

Em razão do avanço da globalização e das transformações na estrutura produtiva, a informalidade passa a adquirir novos significados. No ano de 2002, a OIT formula o conceito de nova informalidade com o intuito de abranger as novas formas desregulamentadas de trabalho. As discussões sobre a nova informalidade passam a reconhecer que a participação na informalidade não é desempenhada exclusivamente por trabalhadores empobrecidos e pouco escolarizados, mas surge como opção para trabalhadores expulsos do mercado formal e para aqueles que, apesar da desproteção social, buscam aumentar seus ganhos monetários em razão da desregulamentação das atividades informais. Embora as práticas laborais designadas no conceito de nova informalidade permaneçam à margem da institucionalização/ regulamentação legal, elas se caracterizam por profunda legitimidade social (LIMA, 2013).

Considerando seus apectos constitutivos, a nova informalidade apresenta inequívoca capacidade de absorção de parcelas significativas de trabalhadores. Todavia, em grande medida ela continua a apresentar face perversa ao trabalhador, especialmente por inseri-lo de forma precária no mercado de trabalho, sem qualquer segurança de permanência estável em seu posto laboral e com profundas implicações em longo prazo, especialmente para aqueles que, por não contribuirem com instituto de previdência, estarão fora da cobertura de pensões e aposentadorias.

5 No ano de 2017 , o governo brasileiro propôs alteração de partes da legislação trabalhista vigente. Um dos pontos polêmicos permite a expansão das práticas de terceirização, possibilitando a terceirização de atividades-fins, isto é, a terceirização de atividades diretamente vinculadas ao objeto social da empresa contratante. O projeto de alteração da legislação trabalhista foi aprovado pelo Congresso Nacional e aguarda sanção da presidência da república.

6 A expressão trabalho informal foi institucionalizada pela Organização Internacional do Trabalho (OIT), em 1972, considerando que a informalidade era parte constitutiva da estrutura socioeconômica dos países subdesenvolvidos, cujas atividades precárias configuravam estratégias de inserção laboral e de sobrevivência de parcelas expressivas de trabalhadores (BARBOSA, 2009). 
No Brasil, são recorrentes os casos de trabalho precário a constituirem-se não como exceções, mas como elemento constitutivo do regime de acumulação. Dados do Censo Demográfico de 2010 indicam que 22,8\% de trabalhadores brasileiros desempenham atividades laborais desinstitucionalizadas, isto é, sem proteção da Consolidação das Leis Trabalhistas (CLT) ou vínculo estatutário e 22,4\% dos trabalhadores não apresentam comprovação quanto à formalização de suas atividades, podendo ser executadas tanto por profissionais liberais que pagam tributos e têm efetivamente garantidos seus direitos trabalhistas e previdenciários, como, de forma oposta, podem ser executadas de maneira informal, isto é, por profissionais autônomos que estão social e juridicamente desprotegidos, o que aumentaria a participação das atividades precárias na composição do mercado de trabalho brasileiro.

Não obstante as características gerais das formas precárias de trabalho, incluindo a nova informalidade, destaca-se que, no contexto brasileiro, tradicionalmente a precarização laboral encontra-se associada a determinados fatores socioeconômicos e demográficos, sendo possível considerar que certas características socioeconômicas e demográficas de grupos populacionais podem influenciar a participação e permanência destes grupos nas formas precárias de trabalho.

Nogueira (2006) e Araújo e Lombardi (2013) destacam a tendência de as mulheres desempenharem atividades informais e receberem menores rendimentos em relação aos homens. Isso se explica pelas dificuldades de inserção das mulheres no mercado de trabalho, que, embora apresentem qualificação mais elevada que os homens, permanecem mais vulneráveis em razão do preconceito que sofrem as mulheres na divisão do trabalho.

Sobre as faixas etárias, existe uma tendência de os jovens e adultos ocuparem os postos formais de trabalho, bem como obterem maiores rendimentos do que crianças e idosos. Para além de questões legais que impendem as crianças de trabalhar, isto se deve ao fato de que os jovens e adultos apresentam maior qualificação educacional e profissional, resultado dos investimentos recentes em educação e também por se encontrarem no auge da produtividade de suas vidas laborais (FREITAS; PAPA, 2003; CASTRO, 2008).

Estudos ressaltam a importância de se investigar as associações entre a escolarização e a precarização. Indivíduos que apresentam maior nível de instrução tendem a desempenhar posições laborais superiores em relação àqueles com menor qualificação educacional, bem como tendem a obter maiores rendimentos, tornando-se relevante analisar as características das funções laborais segundo os diferenciais de escolarização (CASTRO, 2008). 
Com relação à cor/ raça, devido à própria dinâmica brasileira, que em grande medida reproduz a inserção precária dos negros na sociedade pós-escravista, pessoas de cor branca tendem a ocupar em maior proporção os postos de trabalho formais, que exigem maior qualificação educacional e profissional, bem como obter maiores rendimentos, em relação às pessoas que se declaram não brancas, especialmente os negros e pardos. Uma característica marcante é a evidente desvantagem de pessoas negras e pardas na hierarquia de classes, de modo que elas tendem a apresentar os menores escores de qualificação, as menores taxas de ocupação e os menores rendimentos, tornando-se prioritário investigar as influências da cor na estrutura produtiva (CASTRO; BARRETO, 1998).

Por fim, a migração exprime o poder de atração/ repulsão de um território, em função das condições socioeconômicas e culturais que podem motivar fluxos populacionais que buscam oportunidades de trabalho e condições de vida (BECKER, 2006; DUARTE; FUSCO, 2008). Contudo, nem sempre os desejos e as promessas que motivam os deslocamentos populacionais são materializados, sendo relevante analisar os diferenciais de trabalho e condições de vida entre os grupos de migrantes e não migrantes.

Tomando como base os fatores que são associados à precarização das atividades laborais, o presente estudo busca analisar quais fatores socioeconômicos e demográficos estão associados à precarização do trabalho e quais as consequências monetárias disto para os trabalhadores no município de Toritama, cujo mercado de trabalho caracteriza-se por elevado grau de precarização das atividades laborais.

\section{Caracterização histórica e socioeconômica de Toritama e abordagens metodológicas}

O município de Toritama localiza-se na região Agreste do Estado de Pernambuco, na região Nordeste do Brasil. Tradicionalmente, a estrutura socioeconômica das regiões afastadas das capitais e/ ou centros administrativos brasileiros tendem a ter como base a agropecuária e a indústria de transformação vinculada à agropecuária. Em Toritama, contudo, as características naturais da região, aliada à ausência de políticas de convivência com a escassez de chuvas, impedem a expansão das atividades agropecuárias locais.

A vulnerabilidade socioeconômica de Toritama agravou-se na década de 1970 devido à estagnação da agropecuária no Nordeste. Como alternativas, intensificou-se a produção artesanal de calçados de couro e as confecções com retalhos de tecido. Na década de 1980, a confecção de roupas apresentou crescimento na 
demanda e, por isso, foi gradativamente aprimorada nos municípios do Agreste pernambucano, especialmente em Santa Cruz do Capibaribe, Toritama e Caruaru que, juntos, passaram a compor importante centro econômico regional, o Polo de Confecções do Agreste Pernambucano (DUARTE; FUSCO, 2008; RABOSSI, 2008; FUNDAJ, 2008; LIRA, 2011).

A produção de confecção com retalhos de tecido surgiu na década de 1970, a partir do aproveitamento de sobras não utilizadas de tecidos de malha, chamados de helanca, oriundos das indústrias de confecções do Sudeste brasileiro, dando origem ao nome Sulanca, como são popularmente conhecidos os produtos de confecção de baixo custo comercializados em feiras populares. Neste período, começou a funcionar, em Santa Cruz do Capibaribe, a indústria da Sulanca, quando caminhoneiros compravam retalhos do tecido helanca e os comercializavam com as costureiras de Santa Cruz do Capibaribe, a fim de não retornarem aos municípios de origem sem carga para vender, diminuindo, assim, os custos com o transporte (FUNDAJ, 2008; RABOSSI, 2008; LIRA, 2011; OLIVEIRA, 2013).

A indústria de confecções local direcionou sua produção para a linha de produtos populares, fortalecendo o processo de comercialização por meio de grandes feiras de ruas, conhecidas como feiras da Sulanca, nas quais os produtos são expostos e comercializados, intensificando o dinamismo econômico nos municípios do Agreste. O polo de confecções do Agreste pernambucano abastece os mercados local e nacional, inclusive para o mercado internacional, sendo responsável por parte significativa dos jeans produzidos no Brasil (FUNDAJ, 2008; RABOSSI, 2008; LIRA, 2011; VASCONCELOS, 2012; OLIVEIRA, 2013).

A indústria têxtil em Toritama é composta por milhares de pequenos empreendimentos, muitos de base familiar, isto é, produtores individuais e/ ou pequenas empresas que quase sempre funcionam em espaços domiciliares destinados à produção, ocorrendo majoritariamente sob as formas de subcontratação, terceirização e informalidade, convergindo para a maximização dos lucros dos produtores e comerciantes locais (DUARTE; FUSCO, 2008; FUNDAJ, 2008; VASCONCELOS, 2012).

Lima (2013) destaca que os pequenos empreendimentos informais que abastecem grandes empresas são definidos como Sweats Shops, pequenas oficinas e empresas que produzem a custos baixos e com condições de trabalho precárias para bastecer grandes grupos empresariais. A partir da década de 1990, ressalta o autor que o poder público passa a incentivar este tipo de estrutura produtiva por meio de políticas públicas focadas nos Arranjos Produtivos Locais (APL), considerando como práticas exitosas desempenhadas nesses territórios, demonstrando claro 
alinhamento com o discurso do empreendedorismo e da capacidade dinâmica em reduzir os custos de produção e elevar a competitividade.

Com relação às práticas laborais que ocorrem em Toritama, Rabossi (2008) chama a atenção para o entrecruzamento existente entre práticas formais e informais de produção e circulação de mercadorias no contexto do Polo de confecções do Agreste. Diferentemente das definições tradicionais que buscam fazer distinções entre práticas formais/ legais e informais/ ilegais, Rabossi (2008) destaca os somberamentos e as dificuldades em traçar essas fronteiras no contexto de Toritama, dado que as práticas de produção e distribuição de mercadorias perpassam atividades que são juridicamente regulamentadas e outras que são desregulamentadas. Mais do que a imprecisão de fronteiras, o autor sublinha a legitimidade social que as práticas de produção e distribuição das mercadorias apresentam em Toritama, de modo que a legitimidade social dessas práticas se sobrepõe e se impõe às regulamentações legais existentes. Com isto, longe de tais práticas serem ilegais, embora em determinados pontos se desacople das práticas formais, elas representam as formas de ganhos de vida e a estrutura econômica do lugar (RABOSSI, 2008).

O dinamismo econômico de Toritama pode ser observado por meio da análise do Produto Interno Bruto (PIB) do município. Entre os anos 2000 e 2010, o PIB passou de 36 milhões de reais para pouco mais de 223 milhões de reais. Parte significativa da economia local se baseia no setor têxtil, que responde por quase $60 \%$ dos postos de trabalho gerados na região, seguido pelo comércio (15\%). Importa destacar ainda que, em razão do dinamismo econômico, a taxa de desocupação no município é de 6,6\% e que proporciona a elevação na média do rendimento mensal dos trabalhadores, que saltou de 380 reais no ano de 2000 para pouco mais de 554 reais em 2010 (IBGE, 2010a).

A população de Toritama registra aumento populacional significativo, tendo passado de 21.562 habitantes no ano 2000 para 35.554 habitantes em 2010, motivado, principalmente, pela imigração de pessoas em busca de oportunidades de trabalho (FUNDAJ, 2008; VASCONCELOS, 2012). Da população total do município, 18.281 (51,4\%) são imigrantes, sendo que, destes, 29,9\% imigraram nos últimos onze anos (IBGE, 2010a).

Parte significativa da economia do município baseia-se no setor têxtil, que, segundo dados do Censo Demográfico 2010, responde por quase 60\% dos postos de trabalho gerados na região, seguido pelo comércio, que responde por quase $15 \%$ das ocupações existentes no município. Ainda de acordo com dados do IBGE, Toritama apresenta elevado grau de informalidade das atividades 
laborais desempenhadas na região, na qual 94,5\% dos tabalhadores desempenham atividades informais.?

Não obstante a evidente precarização do trabalho e os baixos rendimentos auferidos pelos trabalhadores na cadeia de confecções, as características sócio-históricas de Toritama contribuem para que os trabalhadores precários não reconheçam criticamente a lógica de exploração e de vulnerabilidade na qual eles estão inseridos. No passado recente, a população local buscava sua sobrevivência financeira por meio da agricultura de subsistência em uma região árida, o que demandava longas horas de trabalho numa terra seca, pedregosa e sob o sol, sem perspectivas de elevação de ganhos econômicos. A transformação da estrutura produtiva local, iniciada com a produção de artigos de couro e, posteriormente, em confecções de tecidos, embora baseada na precarização do trabalho, para parcelas significativas de trabalhadores ainda representa a liberdade e a perspectiva de melhores condições de vida futuras (FUNDAJ, 2008; VASCONCELOS, 2012).

Diante das características socioeconômicas e demográficas locais, o presente estudo apresenta como objetivos analisar os fatores de influência na participação dos trabalhadores em atividades precárias e em que medida isto impacta no rendimento dos trabalhadores no município de Toritama. Para isso, são utilizados dados da Amostra do Censo Demográfico de 2010 com vistas a analisar a precarização do trabalho em Toritama a partir de dois indicadores, analisados na qualidade de fatores de efeito: precarização das atividades laborais e média de rendimento obtida no trabalho principal. Com isto, são realizados dois tipos de procedimentos analíticos: análises de correlação e análises de comparações de médias entre os indicadores e os grupos populacionais construídos para o estudo.

$\mathrm{O}$ indicador precarização das atividades laborais ${ }^{8}$ aponta a participação dos trabalhadores no mercado laboral segundo a característica de formalização da atividade principal, a qual permite verificar a proporção de postos de trabalho em condições de precariedade, bem como analisar características

7 Considerou-se como "formal" qualquer ocupação por meio da qual o trabalhador contribuiu com o instituto de previdência social, conforme declarado no Censo Demográfico 2010. Do contrário, considera-se como informal o trabalhador que não contribuiu com instituto de previdência social, segundo a operacionalização do conceito sugerida pelo IPEA (2011).

8 Na construção do indicador "precarização das atividades laborais", a variável "contribui com a previdência social" foi dividida em dois grupos: formais, composto pelos trabalhadores que contribuem com a previdência social, incluindo funcionários públicos, militares, empregados com carteira assinada e profissionais liberais que contribuem com instituto de previdência social; e informais, formado por todos os trabalhadores que não contribuem com instituto de previdência social (IBGE, 2010b; IPEA, 2011). 
socioeconômicas e demográficas que podem estar associadas à precarização do trabalho na região (IBGE, 2010b; IPEA, 2011).

$\mathrm{O}$ indicador média de rendimento obtida no trabalho principal $^{9}$ permite analisar o nível de precarização socioeconômica do trabalhador, sendo possível associar as vantagens/ desvantagens econômicas dos trabalhadores com determinadas características socioeconômicas e demográficas destes trabalhadores. Os dois indicadores supracitados são analisados a partir de cinco grupos populacionais, considerados como fatores de previsão. São eles: sexo, faixas etárias ${ }^{10}$, escolarização $0^{11}$, cor/ raça $a^{12}$ e migração. ${ }^{13}$

Na primeira etapa da investigação, buscou-se analisar a associação entre a variável precarização das atividades laborais e os grupos populacionais selecionados, optando-se pela realização de testes de análises de correlação e significância. Posteriormente, foram analisados os diferenciais de rendimentos entre os grupos populacionais, realizando-se testes de comparações de médias entre as médias de rendimento obtidas no trabalho principal dos grupos populacionais investigados. Por fim, foram realizados testes de correlação e significância entre a variável e os grupos populacionais pesquisados.

\section{Precarização do trabalho: fatores associados e seus impactos 4.1 Fatores associados à formalização}

Para analisar quais fatores e em que medida eles estão associados à precarização do trabalho em Toritama, a variável "precarização da atividade laboral” foi analisada segundo cinco variáveis: sexo, faixas etárias, escolaridade, cor/ raça e migração. Os dados do Censo Demográfico de 2010 revelam que

9 Para a construção da variável "média de rendimento obtida no trabalho principal”, utilizou-se a variável formada pela média do rendimento no trabalho principal (IBGE, 2010b).

10 A variável "Faixas Etárias" é composta por três categorias: crianças/ jovens, formada por pessoas de o a 29 anos de idade; adultos, formada por pessoas de 30 a 64 anos; e idosos, formada por pessoas de 65 anos e mais.

11 A variável "Escolarização" é formada por três categorias: "Sem instrução até ensino fundamental completo", "Ensino médio completo" e "Ensino superior completo".

12 No Censo Demográfico 2010, a variável "cor/ raça" é formada por cinco categorias: branca, negra, parda, amarela e indígena. Na presente investigação, a variável "cor/ raça” é operacionalizada a partir da recodificação das categorias, mantendo-se a categoria "branca" e sendo somadas às demais categorias, originando dois grupos, "brancos" e "não brancos".

13 A variável "Migração" foi construída a partir de duas variáveis do Censo Demográfico 2010: "nasceu no município" e "tempo de moradia no município", originando três categorias: "não migrante", composta pelos indivíduos que nasceram e sempre residiram no município; "migrante", formada pelos indivíduos que residem há menos de 11 anos; e "migrante de estoque", formada pelos indivíduos que residem há 11 anos e mais. 
dos $1.596^{14}$ trabalhadores do município de Toritama, aproximadamente $95 \%$ desempenham atividades informais, confirmando o alto grau de precarização do trabalho na região. Isto reforça a hipótese de que a economia e as atividades laborais em territórios marcados pela pobreza e pela baixa qualificação dependem do alto nível de informalização (ANTUNES, 2006; BARBOSA, 2009).

A análise da variável formalização segundo o sexo revela que os trabalhadores do sexo masculino ocupam proporção levemente maior dos postos de trabalho formais do município (56\%). Todavia, os testes Fi $(0,001)$ e Qui-quadrado $(0,984)$ indicam a rejeição da hipótese de associação entre a formalização no trabalho e o sexo (Tabela 1).

Tradicionalmente, existe uma associação entre o sexo e a precarização, de modo que as mulheres tendem a ocupar em maior proporção os postos de trabalho informais (ARAÚJO; LOMBARDI, 2013). Contudo, devido ao fato de a maioria dos postos de trabalho em Toritama ser do tipo informal (94,5\%), as diferenças quanto à formalização entre homens e mulheres torna-se bastante reduzida, fazendo com que ambos os grupos populacionais sejam absorvidos de forma relativamente homogênea na informalidade.

Tabela 1: Toritama. Participação dos trabalhadores nos postos de trabalho formais e informais segundo o sexo e correlação entre as variáveis. 2010.

\begin{tabular}{|l|c|c|c|c|c|c|}
\hline & \multicolumn{2}{|c|}{ Masculino } & \multicolumn{2}{c|}{ Feminino } & \multicolumn{2}{c|}{ Total } \\
\hline & Casos & $\mathbf{\%}$ & Casos & \% & Casos & $\%$ \\
\hline Formais & 46 & 56,1 & 36 & 43,9 & 82 & 100 \\
\hline Informais & 851 & 56,2 & 699 & 43,8 & 1.514 & 100 \\
\hline Total & 897 & 56,2 & 735 & 43,8 & 1.596 & 100 \\
\hline Fi & 0,001 & & & & & \\
\hline $\begin{array}{l}\text { Significância } \\
\text { (Qui-quadrado) }\end{array}$ & 0,984 & & & & & \\
\hline
\end{tabular}

Fonte: Censo Demográfico 2010, IBGE. Tabulação própria.

Segundo dados do Censo Demográfico de 2010, a análise da precarização da atividade laboral segundo as faixas etárias revela que, em Toritama, os adultos ocupam a maior parte dos postos de trabalho formais ( $78 \%)$, seguidos pelos

14 A amostra de trabalhadores residentes em Toritama é composta por 1.886 casos. O número de 1.596 casos corresponde ao número de pessoas ocupadas que efetivamente responderam à questão sobre a contribuição com o instituto de previdência social. Por essa razão, a amostra de 1.596 pessoas foi utilizada para a composição da amostra de trabalhadores formais e informais em Toritama (IBGE, 2010a). 
jovens (22\%), ao passo que nenhum idoso apresenta formalização no trabalho. Os testes V de Crámer $(0,151)$ e Qui-quadrado $(0,001)$, com nível de significância estatístico de $99 \%$, indicam existência de baixa associação entre a precarização e a faixa etária do trabalhador (Tabela 2).

Os resultados obtidos podem ser explicados pelo fato de a maior parte dos postos de trabalho formais do município ser gerado na administração pública, e, como os adultos estão no auge de sua produtividade laboral e tendem a apresentar maior qualificação educacional/ profissional em relação aos demais grupos etários, eles tendem a ocupar a maior parte dos empregos formais desempenhados na região (FREITAS; PAPA, 2003).

Os dados também corroboram a hipótese de Bezerra (2013), para quem o processo de socialização na informalidade em Toritama estimula que muitas crianças da região desempenhem funções produtivas em pequenas unidades de produção familiar, o que representa substantiva diminuição dos custos da produção. Por esta razão, a maior parte das funções laborais precárias registradas no município é exercida por crianças e jovens.

Os dados apresentados reforçam o panorama de vulnerabilidade que a precarização do trabalho provoca em territórios subdesenvolvidos, que absorve, de forma absolutamente ilegal, crianças no mundo do trabalho, sob o discurso falacioso de que a inserção laboral de crianças pode contribuir para minimizar a pobreza generalizada das famílias nesta região. Contra este falso discurso, ressalte-se que o desempenho precoce de funções produtivas somente favorece a reprodução da pobreza, cuja superação requer a estruturação de um circuito econômico dinâmico e institucionalizado, com trabalhadores devidamente qualificados, prontos a desempenharem funções produtivas formais.

Tabela 2: Toritama. Participação dos trabalhadores nos postos de trabalho formais e informais segundo as faixas etárias e correlação entre as variáveis. 2010.

\begin{tabular}{|l|c|c|c|c|c|c|c|c|}
\hline & \multicolumn{2}{|c|}{$\begin{array}{c}\text { Crianças e } \\
\text { jovens }\end{array}$} & \multicolumn{2}{c|}{ Adultos } & \multicolumn{2}{c|}{ Idosos } & \multicolumn{2}{c|}{ Total } \\
\hline & Casos & $\%$ & Casos & $\%$ & Casos & $\%$ & Casos & $\%$ \\
\hline Formais & 18 & 22,0 & 64 & 78,0 & 0 & 0 & 82 & 100 \\
\hline Informais & 840 & 55,5 & 665 & 43,9 & 9 & 0,6 & 1.514 & 100 \\
\hline Total & 858 & 53,8 & 729 & 45,7 & 9 & 0,6 & 1.596 & 100 \\
\hline V de Crámer & 0,151 & & & & & & & \\
\hline $\begin{array}{l}\text { Significância } \\
\text { (Qui-quadrado) }\end{array}$ & 0,001 & & & & & & & \\
\hline
\end{tabular}

Fonte: Censo Demográfico 2010, IBGE. Tabulação própria. 
Com relação à escolarização, dados do Censo Demográfico 2010 revelam que, dos 1.590 trabalhadores, ${ }^{15} 86 \%$ dos postos informais são ocupados por pessoas sem instrução e até o ensino fundamental completo, 13\% são desempenhados por pessoas que possuem ensino médio completo e apenas 1,1\% são ocupados por pessoas com ensino superior completo. A respeito dos postos de trabalho formais, $67 \%$ são ocupados por pessoas sem instrução e até o ensino fundamental, $21 \%$ de pessoas com o ensino médio e apenas $12 \%$ com o ensino superior. Com vistas a analisar a existência de correlação entre as variáveis formalização e escolarização, o teste de Gama $(-0,513)$ indica que, com significância estatística de $99 \%$, existe forte correlação negativa entre as variáveis. Isto significa que, quanto maior a escolaridade, menor é a proporção de trabalhadores que desempenham atividades laborais informais (Tabela 3 ).

Os resultados obtidos confirmam a hipótese de que a elevação da escolaridade tende a aumentar as chances dos trabalhadores em ocupar melhores posições laborais (CASTRO, 2008). Todavia, os dados alertam para existência de alto contingente de trabalhadores formais que apresentam baixa escolarização, denotando a precariedade geral do mercado laboral na região. Isto reforça a tese de que, em territórios empobrecidos e politicamente desprotegidos, o funcionamento do mercado de trabalho tende a depender da baixa qualificação educacional dos trabalhadores e da alocação destes em postos laborais informais, reproduzido o ciclo de precarização (ANTUNES, 2006; BARBOSA, 2009).

Tabela 3: Toritama. Participação dos trabalhadores nos postos de trabalho formais e informais segundo a escolarização e correlação entre as variáveis. 2010.

\begin{tabular}{|l|c|c|c|c|c|c|c|c|}
\hline & \multicolumn{2}{|c|}{$\begin{array}{c}\text { Sem instrução } \\
\text { e ensino } \\
\text { fundamental }\end{array}$} & \multicolumn{2}{|c|}{ Ensino médio } & \multicolumn{2}{|c|}{ Ensino superior } & \multicolumn{2}{|c|}{ Total } \\
\hline & Casos & $\%$ & Casos & $\%$ & Casos & $\%$ & Casos & $\%$ \\
\hline Formais & 55 & 67,1 & 17 & 20,7 & 10 & 12,2 & 82 & 100 \\
\hline Informais & 1.297 & 86,0 & 194 & 12,9 & 17 & 1,1 & 1.508 & 100 \\
\hline Total & 1.352 & 85,0 & 211 & 13,3 & 27 & 1,7 & 1.590 & 100 \\
\hline Gama & $-0,513$ & & & & & & & \\
\hline $\begin{array}{l}\text { Significância } \\
\text { (Escore Z) }\end{array}$ & 0,001 & & & & & & & \\
\hline
\end{tabular}

Fonte: Censo Demográfico 2010, IBGE. Tabulação própria.

15 A amostra é composta por 1.590 pessoas, e não por 1.596, porque há seis casos na base de dados do Censo Demográfico 2010 em que não foi possível determinar o nível de escolaridade, sendo excluídos do cálculo da amostra de trabalhadores formais e informais de Toritama (IBGE, 2010a). 
Os dados do Censo Demográfico 2010 indicam que, em Toritama, não há diferenciação na alocação dos postos de trabalho formais quanto à cor/ raça dos trabalhadores. Dos escassos postos formais existentes, $51,2 \%$ eram desempenhados por pessoas de cor branca e $48,8 \%$ por pessoas de cor não branca. E entre os postos de trabalho informais, $42,5 \%$ eram exercidos por pessoas de cor branca e $57,5 \%$ por pessoas de cor não branca. Entretanto, os testes Fi $(0,119)$ e Qui-quadrado (0,039), com nível de significância estatística de 95\%, indicam a inexistência de associação significativa entre as variáveis, não sendo possível afirmar que a cor/ raça apresenta relação com a formalização do trabalho no território estudado (Tabela 4).

Os resultados refutam as evidências de que a cor/ raça influencia a precarização do trabalho. A explicação para isto é que, no contexto de Toritama, a maioria absoluta dos trabalhadores desempenham atividades laborais informais, não sendo possível captar diferenças estatisticamente significativas a respeito da precarização laboral segundo a cor.

Tabela 4: Toritama. Participação dos trabalhadores nos postos de trabalho formais e informais segundo a cor e correlação entre as variáveis. 2010.

\begin{tabular}{|l|c|c|c|c|c|c|}
\hline & \multicolumn{3}{|l|}{ Brancos } & \multicolumn{2}{l|}{ Não brancos } & \multicolumn{2}{l|}{ Total } \\
\hline & Casos & $\%$ & Casos & $\%$ & Casos & $\%$ \\
\hline Formais & 42 & 51,2 & 40 & 48,8 & 82 & 100 \\
\hline Informais & 643 & 42,5 & 871 & 57,5 & 1.514 & 100 \\
\hline Total & 685 & 42,9 & 911 & 57,1 & 1.596 & 100 \\
\hline Fi & 0,119 & & & & & \\
\hline $\begin{array}{l}\text { Significância } \\
\text { (Qui-quadrado) }\end{array}$ & 0,039 & & & & & \\
\hline
\end{tabular}

Fonte: Censo Demográfico 2010, IBGE. Tabulação própria.

Com relação à migração, dados do Censo Demográfico 2010 indicam que $51 \%$ dos postos formais são ocupados por "não migrantes", $28 \%$ são exercidos por migrantes de estoque e os $20 \%$ de postos formais restantes são desempenhados por migrantes que residem no município há menos de onze anos no município.

Os testes V de Crámer $(0,048)$ e Qui-quadrado $(0,156)$ indicam existência de baixa associação entre a precarização das atividades laborais e migração no município de Toritama, conforme apresentado na Tabela 5. 
Os resultados obtidos revelam que os migrantes representam o grupo que, proporcionalmente, desempenham menos funções laborais formais, sugerindo haver dificuldades para sua inserção no mercado de trabalho formal. Este dado coincide com a hipótese de que os migrantes, por geralmente serem oriundos de lugares com poucas oportunidades profissionais, por apresentarem baixa qualificação educacional e profissional e por não terem formado sólida rede de apoio no lugar de destino, tendem a encontrar dificuldades de inserção laboral, restando como alternativa inicial a participação em atividades precárias (BECKER, 2006; DUARTE; FUSCO, 2008).

Tabela 5: Toritama. Participação dos trabalhadores nos postos de trabalho formais e informais segundo a migração e correlação entre as variáveis. 2010.

\begin{tabular}{|l|c|c|c|c|c|c|c|c|}
\hline & \multicolumn{2}{|c|}{ Não migrantes } & \multicolumn{2}{|c|}{ Migrantes } & \multicolumn{2}{c|}{$\begin{array}{c}\text { Migrantes de } \\
\text { estoque }\end{array}$} & \multicolumn{2}{c|}{ Total } \\
\hline & Casos & $\%$ & Casos & $\%$ & Casos & $\%$ & Casos & $\%$ \\
\hline Formais & 42 & 51,2 & 17 & 20,7 & 23 & 28,0 & 82 & 100 \\
\hline Informais & 640 & 42,3 & 454 & 30,0 & 420 & 27,7 & 1.514 & 100 \\
\hline Total & 682 & 47,2 & 471 & 29,5 & 443 & 27,8 & 1.596 & 100 \\
\hline V de Crámer & 0,048 & & & & & & & \\
\hline $\begin{array}{l}\text { Significância } \\
\text { (Qui-quadrado) }\end{array}$ & 0,156 & & & & & & & \\
\hline
\end{tabular}

Fonte: Censo Demográfico 2010, IBGE. Tabulação própria.

Os dados apresentados na primeira etapa desta investigação fornece um quadro analítico do mercado laboral em Toritama, caracterizado pela capacidade de absorção de grandes contingentes de trabalhadores sob a condição de precariedade. Este cenário local representa e reforça a ideia global de que, sob a lógica da acumulação flexível, a precariedade não representa uma característica residual, mas, ao contrário, significa a base e força motriz do processo de acumulação, que necessita de um amplo contingente de trabalhadores precarizados, constantemente ameaçados pela sombra do lumpem, para reproduzir o modelo de acumulação capitalista. Este modelo encontra as condições ideais no (des)arranjo institucional dos países subdesenvolvidos, que, sob o discurso da necessidade de atrair investimentos, implodem as condições de dignidade e cidadania de seus trabalhadores em troca de funções laborais desprotegidas, desvalorizadas e ilegais.

O município de Toritama apresenta características singulares que tornam o seu mercado de trabalho mais precário em relação a muitos outros territórios. 
Basta recordar que quase $95 \%$ da força de trabalho local desenvolvem atividades informais. O contexto de Tortiama, embora marcado historicamente por alta desregulamentação do mercado de trabalho, apresenta forte legitimidade social (RABOSSI, 2008), de modo que as práticas de produção e as relações laborais devem ser compreendidas sob o prisma da nova informalidade, ou seja, práticas que são parte constitutiva da economia local e estratégias de sobrevivência dos milhares de trabalhadores nelas envolvidas (LIMA, 2013). Por todas essas razões, torna-se indispensável refletir sobre as consequências disto para os trabalhadores que desempenham as práticas laborais informais.

\subsection{Fatores associados ao rendimento}

Nesta segunda etapa da investigação empírica, buscou-se comparar a existência de correlação entre a média de rendimento obtida no trabalho principal dos trabalhadores de Toritama e os grupos populacionais contidos nas variáveis explicativas. O objetivo é o de demonstrar que, em paralelo à erosão institucional das posições laborais em Toritama, a precarização do trabalho e seus fatores associados também impactam diretamente na condição monetária dos trabalhadores.

Com base na amostra original de 1.886 trabalhadores residentes no município de Toritama, provenientes do Censo Demográfico de 2010, verifica-se que, além do fato de os trabalhadores do sexo masculino ocuparem a maior parte dos postos de trabalho no município de Toritama (56\%), a média do rendimento mensal no trabalho principal dos homens é mais alta que a média do rendimento mensal no trabalho principal das mulheres, com diferença média de 128,21 reais. Ou seja, as trabalhadoras recebem em média $18 \%$ a menos que os trabalhadores.

A diferença entre as médias de rendimentos entre homens e mulheres no município de Toritama é confirmada com base no valor do nível de significância do teste Mann-Whitney (o,001) (Tabela 6). Além disso, o valor do teste Spearman (o,146), com nível de significância estatística de 99\%, confirma a hipótese que existe associação baixa entre sexo e o rendimento mensal no trabalho principal no município de Toritama (Tabela 7).

Os resultados obtidos convergem com os argumentos apresentados por Nogueira (2006) e Araújo e Lombardi (2013) de que as mulheres tendem a apresentar menores rendimentos que os homens, evidenciando a discriminação das mulheres no mercado de trabalho. Em Toritama, o preconceito sofrido pelas mulheres torna-se bastante evidente, de vez que ambos os grupos populacionais inserem-se em atividades laborais igualmente precárias, mas que geram padrões diferenciados de renda entre os sexos. 
Tabela 6: Toritama. Informações relativas ao rendimento mensal segundo o sexo. 2010.

\begin{tabular}{|l|c|c|c|c|}
\hline Sexo & Casos & Média (R\$) & Mediana (R\$) & Desvio Padrão \\
\hline Masculino & 1.057 & 747,16 & 510,00 & 992,889 \\
\hline Feminino & 829 & 618,95 & 510,00 & 853,125 \\
\hline Total & 1.886 & 690,81 & 510,00 & 935,963 \\
\hline $\begin{array}{l}\text { Significância (Mann- } \\
\text {-Whitney) }\end{array}$ & 0,001 & & & \\
\hline
\end{tabular}

Fonte: Censo Demográfico 2010, IBGE. Tabulação própria.

Tabela 7: Toritama. Teste de Rô de Spearman de análise de correlação entre as variáveis rendimento e sexo. 2010.

\begin{tabular}{|l|l|}
\hline Casos & 1.886 \\
\hline Rô de Spearman & $-0,146$ \\
\hline Significância & 0,001 \\
\hline
\end{tabular}

Fonte: Censo Demográfico 2010, IBGE. Tabulação própria.

Com relação às faixas etárias, dados da amostra de 1.886 indivíduos revelam que, em Toritama, o grupo formado por crianças e jovens ocupam quase $54 \%$ dos postos de trabalho existentes, ao passo que os adultos e idosos ocupam $45 \% \mathrm{e}$ $1 \%$ dos demais postos de trabalho, respectivamente. A participação de crianças e jovens no mercado de trabalho local contrasta com os rendimentos monetários obtidos por este grupo etário. Os adultos formam a categoria que apresenta a mais elevada média do rendimento mensal no trabalho principal ( $\mathrm{R} \$ 823,35)$, ganhando aproximadamente $30 \%$ a mais que a média de rendimento mensal de crianças e jovens e quase $70 \%$ a mais que a média de rendimento mensal dos idosos.

Os dados obtidos alertam para a participação significativa de crianças e jovens no mercado de trabalho em Toritama. Isto pode representar um grave problema social, dado que a participação deste grupo em funções produtivas pode significar empecilho à efetiva participação escolar. Segundo Castro (2008), a substituição de atividades escolares por funções produtivas representa grave causa da reprodução da pobreza e do ciclo de precarização do trabalho. Os resultados apresentados convergem com os argumentos presentes em Castro (2008) e em Freitas e Papa (2003), nos quais crianças e jovens tendem a apresentar maior vulnerabilidade no mercado de trabalho, desempenhando funções produtivas precárias e recebendo menores rendimentos em relação aos adultos.

Outra reflexão a ser feita diz respeito à participação dos idosos no mercado de trabalho. Embora este grupo responda por apenas 1\% da participação no mercado 
laboral em Toritama, ele apresenta a menor média de rendimento mensal em relação aos demais grupos etários, o que atesta sua situação de vulnerabilidade. Os casos de idosos que participam ativamente no mercado de trabalho ocorrem, em grande medida, entre aqueles que não dispõem de pensão por aposentadoria ou porque o valor da aposentadoria recebida é baixo em relação aos custos apresentados pelos idosos, que, não raro, participam ativamente da manutenção das famílias brasileiras (WAJNMAN; OLIVEIRA; OLIVEIRA, 2004).

Os resultados obtidos indicam disparidade entre a média de rendimentos no trabalho principal obtida pelos grupos etários. Contudo, o teste Kruskal-Wallis $(0,519)$ demonstra que o resultado obtido na amostra não pode ser expandido para o universo do município de Toritama (Tabela 8). De forma complementar, o teste Eta $(0,134)$ indica baixa correlação entre as variáveis analisadas (Tabela 9). Os resultados rejeitam a hipótese de que existe diferença das médias de rendimento mensal no trabalho principal entre as faixas etárias.

Tabela 8: Toritama. Informações relativas ao rendimento mensal segundo as faixas etárias. 2010.

\begin{tabular}{|l|c|c|c|c|}
\hline Faixas etárias & Casos & Média (R\$) & Mediana (R\$) & Desvio Padrão \\
\hline Crianças/jovens & 1.012 & 586,64 & 510,00 & 396,529 \\
\hline Adultos & 856 & 823,35 & 510,00 & $1.307,14$ \\
\hline Idosos & 18 & 243,89 & 100,00 & 331,35 \\
\hline Total & 1.886 & 690,81 & 510,00 & 935,963 \\
\hline $\begin{array}{l}\text { Significância } \\
\text { (Kruskal-Wallis) }\end{array}$ & 0,519 & & & \\
\hline
\end{tabular}

Fonte: Censo Demográfico 2010, IBGE. Tabulação própria.

Tabela 9: Toritama. Teste de Eta de análise de correlação entre as variáveis rendimento e faixas etárias. 2010.

\begin{tabular}{|l|c|}
\hline Casos & 1.886 \\
\hline Eta & 0,134 \\
\hline Significância (Qui-quadrado) & 0,001 \\
\hline
\end{tabular}

Fonte: Censo Demográfico 2010, IBGE. Tabulação própria.

Com relação à escolarização, constata-se que, dos 1.880 casos incluídos na amostra, 83\% dos trabalhadores situam-se na faixa mais baixa de escolarização e menos de $1 \%$ dos trabalhadores concentra-se na faixa mais alta de escolarização, o que revela a baixa qualificação educacional no município. Os resultados 
obtidos indicam que a média de rendimento mensal no trabalho principal de pessoas com ensino superior é quase o dobro daquela de pessoas que possuem o ensino médio completo e $62 \%$ maior que a média de rendimento no trabalho principal dos trabalhadores sem instrução e com o ensino fundamental completo. Isto demonstra que quanto mais elevada é a faixa de escolarização, maior é a média de rendimento obtido no trabalho principal (Tabela 10).

Os testes Eta $(0,179)$ e Qui-quadrado (o,001) indicam que, com nível de significância estatística de 99\%, é possível afirmar que existe correlação baixa entre o rendimento no trabalho principal e a escolarização no município de Toritama. Isto indica que a escolarização representa um fator relevante para explicar as diferenças de rendimentos dos trabalhadores no município (Tabela 11).

Os dados relativos ao contexto de Toritama confirmam a ideia de que a qualificação educacional apresenta relevância no fortalecimento qualitativo do mercado laboral e no rendimento dos trabalhadores, sendo indispensável priorizar as políticas educacionais como forma de romper com a reprodução de precarização e pobreza (CASTRO, 2008).

Tabela 10: Toritama. Informações relativas ao rendimento mensal segundo escolarização. 2010.

\begin{tabular}{|l|r|r|l|r|}
\hline Escolarização & \multicolumn{1}{|l|}{ Casos } & $\begin{array}{l}\text { Média } \\
(\mathbf{R} \$)\end{array}$ & $\begin{array}{l}\text { Mediana } \\
(\mathbf{R} \$)\end{array}$ & $\begin{array}{l}\text { Desvio } \\
\text { Padrão }\end{array}$ \\
\hline Sem instrução até ensino fundamental & 1.553 & 634,35 & 510,00 & 809,103 \\
\hline Ensino médio & 286 & 860,24 & 600,00 & $1.348,77$ \\
\hline Ensino superior & 41 & $1.672,85$ & $1.200,00$ & $1.258,54$ \\
\hline Total & 1.880 & 691,36 & 510,00 & 937,237 \\
\hline Significância (Kruskal-Wallis) & 0,001 & & & \\
\hline
\end{tabular}

Fonte: Censo Demográfico 2010, IBGE. Tabulação própria.

Tabela 11: Toritama. Teste de Eta de análise de correlação entre as variáveis rendimento e escolarização. 2010.

\begin{tabular}{|l|c|}
\hline Casos & 1.880 \\
\hline Eta & 0,179 \\
\hline Significância (Qui-quarado) & 0,001 \\
\hline
\end{tabular}

Fonte: Censo Demográfico 2010, IBGE. Tabulação própria.

Os dados da amostra do município de Toritama indicam que as pessoas que se declaram de cor não branca ocupam a maior parte dos postos de trabalho 
da região (56\%). Em contrapartida, a média de rendimento mensal no trabalho principal dos não brancos é $11 \%$ menor que aquela obtida pelos trabalhadores de cor branca, denotando diferencial de renda entre os grupos populacionais.

O teste Mann-Whitney $(0,033)$ confirma a existência de diferença significativa entre as médias de rendimento dos dois grupos populacionais no território estudado, de modo que pessoas de cor branca apresentam média de rendimento superior em relação aos não brancos (Tabela 12). Entretanto, os testes Spearman $(0,049)$ e Qui-quadrado $(0,033)$ indicam haver correlação desprezível entre as variáveis média de rendimento no trabalho principal e cor, rejeitando a hipótese de que a cor apresenta associação com a média de rendimento mensal no município de Toritama (Tabela 13).

Os diferenciais de rendimento, aliados a outros indicadores de vulnerabilidade indicam a desvantagem dos não brancos em relação aos brancos no mercado de trabalho. A necessária equidade entre ambos somente poderá ser alcançada mediante políticas públicas que elevem a qualificação educacional e profissional destes, fortalecendo sua participação em posições laborais hierarquicamente superiores (CASTRO; BARRETO, 1998).

Tabela 12: Toritama. Informações relativas ao rendimento mensal segundo a cor. 2010.

\begin{tabular}{|l|l|l|l|l|}
\hline Cor & Casos & Média $(\mathbf{R})$ & Mediana $($ R\$) & Desvio Padrão \\
\hline Brancos & 824 & 736,19 & 510,00 & $1.045,51$ \\
\hline Não-brancos & 1.062 & 655,59 & 510,00 & 840,02 \\
\hline Total & 1.886 & 690,81 & 510,00 & 935,963 \\
\hline Mann-Whitney & 0,033 & & & \\
\hline
\end{tabular}

Fonte: Censo Demográfico 2010, IBGE. Tabulação própria.

Tabela 13: Toritama. Teste de Rô de Spearman de análise de correlação entre as variáveis rendimento e cor. 2010.

\begin{tabular}{|l|l|}
\hline Casos & 1.886 \\
\hline Rô de Spearman & $-0,049$ \\
\hline Significância & 0,033 \\
\hline
\end{tabular}

Fonte: Censo Demográfico 2010, IBGE. Tabulação própria.

Com relação à migração, tomando-se como base a amostra do Censo Demográfico 2010, verifica-se que a maior parte dos trabalhadores é composta por não migrantes $(40 \%)$ seguida pelos migrantes $(32 \%)$ e pelos migrantes de 
estoque (28\%). O grupo composto pelos não migrantes apresenta média do rendimento mensal no trabalho principal superior ao valor apresentado pelo grupo de migrantes (diferença de quase 100 reais a mais) e dos migrantes de estoque (diferença de pouco mais de 70 reais).

As baixas diferenças nas médias de rendimento no trabalho principal obtidas na amostra fazem com que o teste Kruskal-Wallis $(0,510)$ indique inexistência de diferença estatisticamente significativa entre os grupos analisados, conforme indicado na Tabela 14. Por sua vez, o teste Eta $(0,047)$, com nível de significância estatística de 99\%, indica a existência de correlação desprezível entre as variáveis migração e rendimento no trabalho principal, não sendo possível confirmar a associação entre a média de rendimento no trabalho principal e a migração no município de Toritama (Tabela 15).

Levando-se em consideração a variável média de rendimento no trabalho principal como indicador da qualidade de participação laboral, os resultados obtidos refutam a tese presente em Becker (2006) de que a condição migratória tende a influenciar a participação laboral na medida em que os não migrantes tendem a apresentar melhores condições de participarem adequadamente no mercado de trabalho.

Tabela 14: Toritama. Informações relativas ao rendimento mensal segundo a migração. 2010.

\begin{tabular}{|l|c|c|c|c|}
\hline Migração & Casos & Média (R\$) & Mediana (R\$) & Desvio Padrão \\
\hline Não-migrante & 762 & 742,27 & 510,00 & $1.134,16$ \\
\hline Migrante & 599 & 643,86 & 510,00 & 902,52 \\
\hline Migrante estoque & 525 & 669,67 & 510,00 & 588,96 \\
\hline Total & 1.886 & 690,81 & 510,00 & 935,963 \\
\hline $\begin{array}{l}\text { Kruskal-Wallis } \\
\text { (Significância) }\end{array}$ & 0,510 & & & \\
\hline
\end{tabular}

Fonte: Censo Demográfico 2010, IBGE. Tabulação própria.

Tabela 15: Toritama. Teste de Eta de análise de correlação entre as variáveis rendimento e migração. 2010.

\begin{tabular}{|l|l|}
\hline Casos & 1.886 \\
\hline Eta & 0,047 \\
\hline Significância (Qui-quadrado) & 0,001 \\
\hline
\end{tabular}

Fonte: Censo Demográfico 2010, IBGE. Tabulação própria. 
Com base na amostra de 1.596 trabalhadores, os dados revelam diferença entre as médias de rendimento no trabalho principal obtidas por trabalhadores formais e informais, cujos trabalhadores formais recebem em média três vezes mais que aqueles informais. $\mathrm{O}$ teste Mann-Whitney $(0,001)$ confirma a diferença estatisticamente significativa entre as médias de rendimento apresentada pelos dois grupos populacionais (Tabela 16). Adicionalmente, o teste Spearman $(0,208)$, com nível de significância estatística de $99 \%$, indica existência de correlação moderada entre o rendimento obtido no trabalho principal e a formalização dos trabalhadores em Toritama (Tabela 17).

Os resultados obtidos indicam que a variável formalização apresenta forte capacidade explicativa sobre o rendimento dos trabalhadores em Toritama. Isto corrobora a hipótese de que a formalização é o principal fator de influência nas condições de trabalho e renda dos indivíduos (NORONHA, 2003; ANTUNES, 2006; BARBOSA, 2009).

Tabela 16: Toritama. Informações relativas ao rendimento mensal segundo a formalização. 2010.

\begin{tabular}{|l|l|l|l|l|}
\hline Formalização & Casos & Média (R\$) & Mediana (R\$) & Desvio Padrão \\
\hline Formais & 82 & $2.002,00$ & $1.010,00$ & $2.876,74$ \\
\hline Informais & 1.514 & 636,00 & 510,00 & 717,412 \\
\hline Total & 1.596 & 707,00 & 510,00 & 999,69 \\
\hline Mann-Whitney & 0,001 & & & \\
\hline
\end{tabular}

Fonte: Censo Demográfico 2010, IBGE. Tabulação própria.

Tabela 17: Toritama. Teste de Rô de Spearman de análise de correlação entre as variáveis rendimento e formalização. 2010.

\begin{tabular}{|l|l|}
\hline Casos & 1.886 \\
\hline Rô de Spearman & $-0,208$ \\
\hline Significância & 0,001 \\
\hline
\end{tabular}

Fonte: Censo Demográfico 2010, IBGE. Tabulação própria.

Os dados apresentados na segunda seção desta investigação revelam que os fatores sexo, escolaridade, cor/ raça e condição migratória, em certa medida, apresentam influência nos rendimentos dos trabalhadores de Toritama. Contudo, de forma inequívoca, a formalização do trabalho é o fator que provoca maiores diferenciais nos rendimentos, de modo que os trabalhadores formais tendem a receber quase três vezes mais que os trabalhadores informais. Este 
dado reforça a ideia de que, contra os argumentos falaciosos de que a flexibilização do trabalho pode apresentar vantagens aos trabalhadores, na realidade, representa não apenas a desvalorização institucional e simbólica do trabalho, como impacta diretamente nos rendimentos dos trabalhadores, ameçando a sobrevivência física dos trabalhadores e de suas famílias, posicionando-os cada vez mais no limite absurdo entre o trabalhador pobre e o miserável sem trabalho.

\section{Considerações finais}

Passados mais de 40 anos desde a institucionalização do conceito de informalidade e das críticas ao modelo de acumulação flexível, permanece em aberto grave contradição a respeito do trabalho precário: apresenta-se como parte constitutiva das economias subdesenvolvidas e com inegável capacidade de expansão quantitativa do mercado de trabalho, porém, reforça a exploração e a precarização dos trabalhadores inseridos no mercado laboral precário.

O universo da precarização no município de Toritama é ínfimo diante das complexas metrópoles que se organizam e funcionam sob a lógica da reestruturação capitalista. Todavia, sua análise apresenta importância na medida em que revela a existência de um lugar, localizado no país que se orgulha em apresentar-se como a oitava maior economia do mundo e modelo de desenvolvimento para os países emergentes, mas que, paradoxalmente, sua economia e população dependem quase exclusivamente da precarização.

A pujança econômica de Toritama retroalimenta-se de um contingente de trabalhadores empobrecidos e fragilizados que sobrevivem por meio da precariedade. Buscando retomar o diálogo com a literatura que versa sobre a precarização do trabalho e, sobretudo, com a nova informalidade, os dados referentes ao município de Toritama revelam que as práticas laborais informais apresentam papel de destaque na absorção de grandes contingentes de trabalhadores no mercado de trabalho local, cuja existência e funcionamento é indispensável nas sociedades capitalistas (KUMAR, 1997; CASTEL, 1998; GRINT, 2002; HARVEY, 2006). Adicionalmente, não se desconsidera que as mudanças recentes no processo de globalização, na estrutura produtiva e nos mercados de trabalho alteraram significativamente a face da informalidade, ampliando a participação de trabalhadores, inclusive altamente qualificados, e diluindo o quadro de vulnerabilidade socioeconômica que é associado à precarização (RABOSSI, 2008; BARBOSA, 2009; LIMA, 2013).

Todavia, o contexto analisado em Toritama revela que as práticas de trabalho informal continuam a trazer desvantagens aos trabalhadores, sobretudo 
quando comparados aos trabalhadores formais, que apresentam rendimento quase três vezes maior que os trabalhadores informais. Os resultados alertam para a urgência de se investigar as articulações entre a lógica de produção capitalista e a contínua expansão da precarização, especialmente em territórios subdesenvolvidos, onde a fragilidade socioeconômica e jurídica das camadas mais pobres da população as pressiona a se inserirem de forma precária no mercado laboral.

A análise deste cenário indica que a questão da precarização não pode ser solucionada simplesmente por meio da criminalização das práticas informais e a formulação e aplicação de leis que proibam o desempenho de atividades consideradas precárias, uma vez que toda a dinâmica socioeconômica local depende da precarização para sua sobrevivência e reprodução. A solução da precarização do trabalho, ainda que necessite de políticas setoriais focadas no trabalho, precisa estar vinculada às urgentes transformações na própria estrutura socioeconômica e política contemporânea, o que faz com que as possibilidades de mudança não pareçam estar no horizonte recente das sociedades capitalistas, especialmente nos territórios subdesenvolvidos.

\section{Referências}

ANTUNES, R. Riqueza e miséria do trabalho no Brasil. São Paulo: Boitempo, 2006.

ARAÚJO, Â. M. C.; LOMBARDI, M. R. Trabalho informal, gênero e raça no Brasil do início do século XXI. Cad. Pesqui., São Paulo, V. 43, n. 149, pp. 452-477, 2013.

BARBOSA, A. De "setor" para "economia informal": aventuras e desventuras de um conceito. Texto baseado na pesquisa de pós-doutorado realizada pelo autor no CEM/CEBRAP. São Paulo, 2009.

BECKER, O. S. Mobilidade espacial da população: conceitos, tipologias, contextos. In: Castro, I. et. al. Explorações geográficas. Rio de Janeiro: Bertrand Brasil, 2006.

BEZERRA, E. M. O trabalho das mulheres na origem e desenvolvimento do Polo de confecções do Agreste de Pernambuco. In: OLIVEIRA, R. V.; SANTANA, M. Aurélio. (Orgs.). Trabalho em territórios produtivos reconfigurados no Brasil. João Pessoa: Editora da UFPB, 2013.

CACCIAMALI, M. C. A economia informal 20 anos depois. Indicadores da FEE, v.21, n. 4, Porto Alegre. PDF. 1994.

CASTEL, R. As metamorfoses da questão social: uma crônica do salário. $6^{\mathrm{a}}$ ed. Petrópolis, RJ: Vozes, 1998.

CASTRO, N. A.; BARRETO, V. S. (Orgs.). Trabalho e desigualdades raciais: negros e brancos no mercado de trabalho em Salvador. São Paulo: Annablume, 1998. 
CASTRO, A. T. B. de. Tendências e Condições da Educação pública no Brasil: a crise na universidade e as cotas. In: BOSCHETTI, I. et al. (Orgs.). Política social no capitalismo: tendências contemporâneas. São Paulo: Cortez, 2008.

DUARTE, R.; FUSCO, W. Migração e emprego precário em dois contextos distintos: São Paulo e Toritama. Cadernos CRH, v. 21, n. 53, p. 337-347, 2008.

FREITAS, M. V. de; PAPA, F. de C. (Orgs.). Políticas públicas de juventude: juventude em pauta. São Paulo: Cortez, 2003.

GRINT, K. Sociologia do trabalho. Lisboa: Piaget, 2002.

HARVEY, D. Condição pós-moderna. São Paulo: Edições Loyola, 2008.

IBGE. Instituto Brasileiro de Geografia e Estatística. Microdados da amostra do Censo Demográfico 2010. Rio de Janeiro: IBGE, 2010a.

. Notas metodológicas do Censo Demográfico 2010. Disponível em: <http:// www.ibge.gov.br>. 2010 .

IPEA. Instituto de Pesquisas Econômicas e Aplicadas. Mercado de trabalho: conjuntura e análise. PDF. 2011.

JINKINGS, I.; AMORIM, E. Produção e desregulamentação na indústria têxtil e de confecção. In: Antunes, R. Riqueza e miséria do trabalho no Brasil. São Paulo: Boitempo, 2006.

KUMAR, K. Da sociedade pós-industrial à pós-moderna: novas teorias sobre o mundo contemporâneo. Rio de Janeiro: Jorge Zahar, 1997.

LIMA, J. C. A nova informalidade. In: IVO, Anette B. (Coord.). Dicionário temático desenvolvimento e questão social: 81 problemáticas contemporâneas. São Paulo: Annablume, 2013. Pp. 330-336.

LIRA, S. Muito além das feiras da sulanca: a produção de confecção no Agreste pernambucano. Recife: Ed. Universitária da UFPE, 2011.

MELO, M. L. de. Os agrestes: estudo dos espaços nordestinos do sistema gado-policultura de uso dos recursos. Recife: Sudene, 1980.

NOGUEIRA, C. M. A feminização do trabalho no mundo do telemarketing. In: ANTUNES, R. Riqueza e miséria do trabalho no Brasil. São Paulo: Boitempo, 2006.

NORONHA, E. "Informal”, ilegal, injusto: percepções do mercado de trabalho no Brasil. RBCS, V. 18, n. 53, pp. 111-129, 2003.

OLIVEIRA, R. V. O Polo de confecções do Agreste de Pernambuco: elementos para uma visão panorâmica. In: OLIVEIRA, R. V.; SANTANA, M. A. (Orgs.). Trabalho em territórios produtivos reconfigurados no Brasil. João Pessoa: Editora da UFPB, 2013. PINHEIRO, I. A. A externalização de atividades: fundamentos e experiências no setor de autopeças gaúcho. Revista de Administração Contemporânea, 3 (2), p.137-165, 1999. RABOSSI, F. En la ruta de las confecciones. Revista crítica en desarollo, n. 02, Buenos Aires, 2008, pp. 151-171. 
VASCONCELOS, V. M. Migração e pendularidade: as consequências da atração da população para o município de Toritama. Dissertação (Mestrado) defendida no Programa de pós-graduação em Geografia da Universidade Federal de Pernambuco. 2012.

WAJNMAN, Simone; OLIVEIRA, Ana Maria; OLIVEIRA, Elzira Lúcia. Os idosos no mercado de trabalho: tendências e consequências. PDF. 2004.

Recebido em 04/08/2016

Aprovado em 13/12/2017

\section{Como citar este artigo:}

SANTOS, Breno Bittencourt; VASCONCELOS, Valtemira Mendes. Fatores socioeconômicos e demográficos associados ao trabalho informal: o caso de Toritama, Pernambuco, Brasil. Contemporânea - Revista de Sociologia da UFSCar, v. 8, n. 1, jan.- jun. 2018, pp. 289-316. 